\title{
Ultrasound guided percutaneous biopsy of omentum: a safest technique to detect the causes of omental thickening
}

\author{
Junaid Iqbal $^{1 *}$, Nauman Al-Qamari², Amjad Sattar², Sadia Rashid ${ }^{3}$
}

${ }^{1}$ Department of Radiology, Dr. Ziauddin University Hospital, Karachi, Pakistan

${ }^{2}$ Department of Radiology, Dow University of Health Sciences, Karachi, Pakistan

${ }^{3}$ Department of Radiology, Patel Hospital, Karachi, Pakistan

Received: 05 May 2021

Accepted: 29 May 2021

\section{*Correspondence:}

Dr. Junaid Iqbal,

Email: junaid2008@gmail.com

Copyright: (C) the author(s), publisher and licensee Medip Academy. This is an open-access article distributed under the terms of the Creative Commons Attribution Non-Commercial License, which permits unrestricted non-commercial use, distribution, and reproduction in any medium, provided the original work is properly cited.

\section{ABSTRACT}

Background: The objective of our study was to determine the diagnostic value and safety of ultrasound guided percutaneous biopsy of omental thickening.

Methods: We prospectively analyzed 60 patients who underwent USG-guided omental biopsies in our institute from January 2016 to December 2016.

Results: Total 60 patients were included in our study. There were $40(66.7 \%)$ female and $20(33.3 \%)$ male patients. There were total $36(60 \%)$ malignant cases, $20(33.3 \%)$ chronic inflammation suggestive of TB while $4(6.7 \%)$ were chronic peritoneal infection. Out of 36 malignant cases, majority $24(66.7 \%)$ had ovarian cancer, $8(22.2 \%)$ had endometrium cancer and $4(11.1 \%)$ had large bowel cancer. Repeat biopsies were performed only in $4(6.7 \%)$ cases. Conclusions: Ultrasound-guided percutaneous biopsy of omentum is less expensive, safe and effective method with a high diagnostic accuracy.

Keywords: Biopsy, Ultrasonography, Omental thickening

\section{INTRODUCTION}

The omentum is the folds of peritoneum. Because a small amount of fluid is present in the peritoneal cavity, infections and malignancy easily spread to the omentum. Ovarian and gastrointestinal malignancies are the commonest neoplasms that involve omentum. Other nonneoplastic causes that involve omentum include granulomatous inflammation, infections and hematoma. ${ }^{1-3}$ Patients with peritoneal diseases presented with ascites, abdominal distention and pain. It is necessary to diagnose the etiology of peritoneal disease for proper treatment. The conventional imaging like ultrasound and CT scan have a low specificity and sensitivity to determine the etiology. That's why a biopsy is often necessary to confirm the diagnosis. Up to the present, only a few reports on patients with peritoneal lesions undergoing imaging-guided percutaneous biopsy have been published. ${ }^{4,5}$

An omental biopsy can be attempted when the omentum is thickened. Conventionally, omental biopsy has been performed by laparotomy or laparoscopy, which has high diagnostic accuracy, but is also associated with many complications, and requires anesthesia and additional costs of hospitalization. For these reasons, laparoscopy is not a suitable option for peritoneal biopsies. ${ }^{1}$ CT-guided percutaneous biopsy is not a real-time procedure, and also involves bowel related complications and risk of radiation. ${ }^{4}$ Ultrasonography is an ideal method for imaging and for guiding a biopsy. The omentum is easily visible on ultrasound when it is thickened. The omentum is easily accessible and can easily be differentiated from bowel because it is real-time imaging. ${ }^{1}$ The purpose of this study is to evaluate diagnostic accuracy and safety of 
ultrasound-guided percutaneous biopsy of omental thickening and to evaluate its etiology.

\section{METHODS}

\section{Data collection procedure}

We prospectively analyzed 60 patients who underwent USG-guided omental biopsies in our institute from January 2016 to December 2016. All patients of either gender, more than 18 years of age and presented with ascites and/or abdominal distention were included. Ultrasonography showed omental thickening (more than $10 \mathrm{~mm}$ ) in all cases. Bleeding parameters were checked before the procedure which included prothrombin time (PT), partial thromboplastin time (PTT), and platelet count. A platelet count above $80000 / \mu \mathrm{l}$ and INR (international normalized ratio) less than 1.2 were considered acceptable for the procedure. All patients signed informed consent forms after details of the procedure were explained.

The procedure was performed in the supine position. Before the biopsy, ultrasonography was performed by using 3.5-5 MHz convex array transducers to show the site of maximum thickness, determine amount of ascites and evaluate adjacent bowel loops by looking for peristalsis. The color Doppler imaging was also performed to see the vascularity in the omental lesions and to see adjacent large vessels. If large amount of ascites is present, we routinely tapped before biopsy.

The needle entry site was marked on the patient's skin by marker. The surrounding area was scrubbed with povidone iodine solution; $3-5 \mathrm{ml}$ of local anesthetic ( $2 \%$ lidocaine hydrochloride) was administered subcutaneously with a 23-gauge needle in the abdominal wall. A tiny incision (2-3 mm wide) was made in the skin, and a biopsy needle was placed straight into the deep layer of the abdominal wall.

Semi automatic biopsy guns with 18- or 16-gauge biopsy needles were used for the biopsy. The sampling length was adjusted to 10 or $20 \mathrm{~mm}$ depending on the thickness of omentum. The needle was advanced into the thickened omentum under real-time Ultrasound guidance, when needle tip reached the omentum, the patient was asked to hold his/her breath and biopsy was performed, usually two core of tissue were taken from each patient. The biopsy specimen was preserved in formaline and sent for histopathological examination. After the procedure the patients were monitored in the recovery room for 3-6 hours.

\section{Statistical analysis}

Statistical package for social sciences (SPSS) version 21 was used for statistical analysis. Mean and standard deviation was calculated for quantitative variables like age of the patients while frequency and percentages were calculated for qualitative variables like gender, diagnosis and status of repeat biopsy. Comparison of age and gender was done with respect to diagnosis of the patients. One-way ANOVA test was applied to see the association of age and diagnosis whereas Chi-square test was applied for gender and diagnosis of the patients, $\mathrm{p}<0.05$ was considered as significant.

\section{RESULTS}

\section{Baseline characteristics}

Total 60 patients were included in the study. Mean age of the patients was $46.33 \pm 13.81$ years (range $25-71$ years). Female preponderance was found to be higher 40 $(66.7 \%)$ as compared to males $20(33.3 \%)$.

\section{Diagnosis and its comparison}

There were total $36(60 \%)$ malignant cases, $20(33.3 \%)$ chronic inflammation suggestive of TB while $4(6.7 \%)$ were chronic peritoneal infection. Out of 36 malignant cases, majority 24 (66.7\%) had ovarian cancer, 8 (22.2\%) had endometrium cancer and $4(11.1 \%)$ had large bowel cancer. Repeat biopsies were performed only in $4(6.7 \%)$ cases with ovarian cancer.

Significant association of gender was observed with diagnosis of the patients $(\mathrm{p}<0.001)$ (Table 1). Mean age of the patients was found insignificantly higher among patients with chronic peritoneal infection while lower in patients with malignant ovarian cancer (Figure 1).

Table 1: Comparison of diagnosis with baseline characteristics of the patients.

\begin{tabular}{|c|c|c|c|c|c|c|}
\hline Parameters & $\begin{array}{l}\text { Chronic } \\
\text { inflammation } \\
\text { suggestive of } \\
\text { TB }(\mathbf{N}=20)\end{array}$ & $\begin{array}{l}\text { Chronic } \\
\text { peritoneal } \\
\text { infection } \\
(\mathrm{N}=4)\end{array}$ & $\begin{array}{l}\text { Malignant } \\
\text { (Ca large } \\
\text { bowel) } \\
(\mathrm{N}=4)\end{array}$ & $\begin{array}{l}\text { Malignant (Ca } \\
\text { endometrium) } \\
(\mathrm{N}=\mathbf{8})\end{array}$ & $\begin{array}{l}\text { Malignant } \\
\text { (Ca ovary) } \\
(\mathrm{N}=24)\end{array}$ & $P$ value \\
\hline Age (years) & $47.60 \pm 14.78$ & $55.50 \pm 6.35$ & $51.5 \pm 9.81$ & $51.0 \pm 8.17$ & $41.33 \pm 14.71$ & $0.16^{\dagger}$ \\
\hline Female N (\%) & $8(20)$ & $0(0)$ & $0(0)$ & $8(20)$ & $24(60)$ & \multirow{2}{*}{$<0.001^{\ddagger}$} \\
\hline Male N (\%) & $12(60)$ & $4(20)$ & $4(20)$ & - & - & \\
\hline
\end{tabular}

One-way ANOVA, ${ }^{\ddagger} \mathrm{Chi}$-square test applied 


\section{Complications}

Four patients had inadequate sample on histopathology in which repeat biopsies were performed. Ten patients experienced abdominal pain, six of them relieved without treatment while four relieved with analgesics. No major complication was observed in our study.

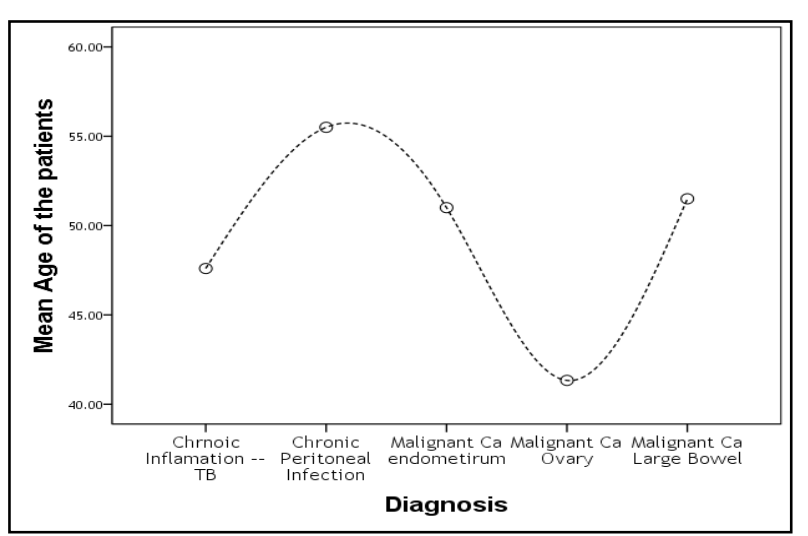

Figure 1: Comparison of mean age of patients with chronic peritoneal diseases and malignant cancers.

\section{DISCUSSION}

The peritoneum is the largest serous membrane in the body with complex structure. The peritoneal reflections form the greater and lesser omentums, which are doublelayered extensions of the peritoneum that connect the stomach to adjacent organs. The natural flow of peritoneal fluid determines the route of spread of intraperitoneal fluid as well as disease processes in the abdominal cavity. ${ }^{2,3}$ The main functions of peritoneum are to protect the abdominal organs and to limit inflammatory diffusion. At the same time, the peritoneum can be infected easily through inflammation, tumors and other diseases of the abdominal organs at an early stage. ${ }^{4}$ The peritoneum and omentum can be involved by metastatic disease, primary tumors, infections, inflammatory conditions, and hemorrhage. Tumors causing omental thickening commonly arising from the ovary, uterus, cervix, stomach, colon, pancreas and lymphoproliferative malignancies., ${ }^{3,6-8}$ Tumour involve omentum by seeding of tumor cells via intraperitoneal dissemination, along with peritoneal reflections and ligaments and also hematogenously. In inflammatory conditions like tuberculosis, the omentum is involved by hematogenous spread from the lungs, by the lymphatics or direct spread. ${ }^{1}$

Although surgical biopsy is the gold standard, abdominal surgery or laparoscopy can detect peritoneal lesions and allow biopsies to be obtained from various parts of peritoneal lesions. However, this is associated with various complications and need for anesthesia. These drawbacks prevent laparoscopy from being popular. Currently patients with peritoneal or omental lesions imaging-guided percutaneous biopsies are commonly performed. ${ }^{4}$ Fine needle aspiration cytology can be performed but it has a low diagnostic accuracy. In contrast, image guided percutaneous biopsies are easy to perfom, it is safe, has a low incidence of injury and other serious complications; it also has a high diagnostic accuracy, which makes it very popular now a days. .,9-12 $^{4}$ USG-guided biopsy is gaining widespread acceptance as it is quicker and less expensive. It is real time imaging and allows visualization of the needle during the procedure, it is not associated with radiation hazards as compared to CT-guided biopsy.,3,9,10 The literature regarding USG guided omental biopsy is limited. ${ }^{9}$ Gottlieb et al in his study on ultrasound guided biopsy of extravisceral masses in peritoneal cavity, they achieved a sensitivity of $93 \%$ and a specificity of $100 \%$ with nondiagnostic samples in $4 \%$ of patients and there was no procedure-related complications. ${ }^{1}$ In our study we obtained positive diagnostic results in $93.3 \%$ of the patients and non diagnostic or inadequate samples were seen in $6.6 \%$ of patients, they all underwent repeat biopsies and got diagnostic results.

The learning points of our study are to provide diagnostic results with minimum or no complications. This is achieved by taking adequate samples/tissue core from the site of maximum omental thickening. The sample/core length should be as large as possible $(20 \mathrm{~mm})$ for positive diagnosis. If the omentum is thinner, the biopsy needle angle should be changed to obtain long core of tissue. The position of the whole biopsy needle and its tip should be clearly displayed on real time ultrasonography. The biopsy should never be performed blindly; otherwise, adjacent organs and bowel loops may be injured. In those patients with large amount of ascites, biopsy should be performed after ascetic fluid drainage for adequate hemostasis.

Safety has been regarded as a key value of ultrasoundguided percutaneous biopsies, and many studies have already proven that this method is one of the safest to

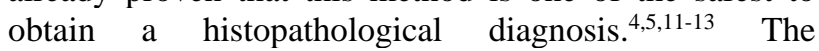
anatomical features of the peritoneum and omentum show that most of the omental lesions are superficial, adjacent to the abdominal wall. Therefore, during the biopsy, the underlying organs are not affected. In addition the entire biopsy process can be monitored by real time ultrasonography. Even if complications like bleeding occur, the ultrasound transducer can stop the bleeding with continuous pressure. ${ }^{4}$ Patients presented with ascites and/or abdominal distension or pain with omental thickening detected on imaging, an ultrasound-guided percutaneous biopsy is less expensive, safe and effective method with a high diagnostic accuracy. Even when a negative result is obtained, repeat percutaneous biopsy should be considered.

\section{CONCLUSION}

Ultrasound-guided percutaneous biopsy of omentum is a less expensive, safe and effective method with a high diagnostic accuracy. 
Funding: No funding sources

Conflict of interest: None declared

Ethical approval: The study was approved by the Institutional Ethics Committee

\section{REFERENCES}

1. Govindarajan P and Keshava SN. Ultrasound-guided omental biopsy: Review of 173 patients. Indian J Radiol Imaging. 2010;20(4):307-9.

2. Yoo E, Kim JH, Kim MJ, Yu JS, Chung JJ, Yoo HS, et al. Greater and lesser omenta: Normal anatomy and pathologic processes. Radiographics. 2007;27: 707-20.

3. Souza FF, Mortelé KJ, Cibas ES, Erturk SM, Silverman SG. Predictive Value of percutaneous imaging-guided biopsy of peritoneal and omental masses: Results in 111 Patients. AJR Am J Roentgenol. 2009;192:131-6.

4. Wang J, Gao L, Tang S, Li T, Lei Y, Xie H, et al. A retrospective analysis on the diagnostic value of ultrasound-guided percutaneous biopsy for peritoneal lesions. World J Surg Oncol. 2013;11:251.

5. Que Y, Wang X, Liu Y, Li P, Ou G, Zhao W. Ultrasound-guided biopsy of an effective method to trace the origin of unclear ascites. Eur $\mathbf{J}$ Radiol. 2009;11:331-5.

6. Layfield LJ, Gopez EV. Percutaneous image-guided fine-needle aspiration of peritoneal lesions. Diagn Cytopathol. 2003;28:6-12.

7. Stewart CJR, Coldwey J, Stewart IS. Comparison of fine needle aspiration cytology and needle core biopsy in the diagnosis of radiologically detected abdominal lesions. J Clin Pathol. 2002;55:93-7.
8. Kim HC, Lee JM, Kim SH. Primary gastrointestinal stromal tumors in the omentum and mesentery: CT findings and pathologic correlations. AJR. 2004;182: 1463-7.

9. Ho LM, Thomas J, Fine SA, Paulson EK. Usefulness of sonographic guidance during percutaneous biopsy of mesenteric masses. AJR Am J Roentgenol. 2003; 180:1563-6.

10. Spencer JA, Swift SE, Wilkinson N, Boon AP, Lane G, Perren TJ. Peritoneal carcinomatosis: imageguided peritoneal core biopsy for tumor type and patient care. Radiology. 2001;221:173-7.

11. Memel DS, Dodd GD, Esola CC. Efficacy of sonography as a guidance technique for biopsy of abdominal, pelvic and retroperitoneal lymph nodes. Am J Roentgenol. 1996;11:957-62.

12. Smith EH. Complications of percutaneous abdominal fine-needle biopsy: review. Radiology.1991;11:2538.

13. Tudor GR, Rodgers PM, West KP. Bowel lesions: percutaneous US-guided 18-gauge needle biopsy preliminary experience. Radiology. 1999;11:594-7.

14. Rana SS, Bhasin DK, Srinivasan R, Singh K. Endoscopic ultrasound-guided fine needle aspiration of peritoneal nodules in patients with ascites of unknown cause. Endoscopy. 2011;11:1010-3.

Cite this article as: Iqbal J, Al-Qamari N, Sattar A, Rashid S. Ultrasound guided percutaneous biopsy of omentum: a safest technique to detect the causes of omental thickening. Int J Basic Clin Pharmacol2021;10:781-4. 